\title{
HARP Versus SinMod for measuring regional heart function from tagged CMR images
}

\author{
El-Sayed H Ibrahim", Scott Swanson, Jadranka Stojanovska, Claire Duvernoy, Rodica Pop-Busui \\ From 19th Annual SCMR Scientific Sessions \\ Los Angeles, CA, USA. 27-30 January 2016
}

\section{Background}

CMR tagging is a valuable technique for evaluating regional heart function. Currently, there are a number of different techniques for analyzing the tagged images, which are based on different analysis algorithms. The purpose of this study is to compare the harmonic phase (HARP) and sine-wave modeling (SinMod) tagging analysis techniques for evaluating myocardial strain and torsion in healthy controls (HC) and patients with type-1 diabetes (T1DM).

\section{Methods}

13 T1DM patients and 8 matched HC (Figure 1) underwent CMR exam that included cine, tagged, and mitral flow images, which were analyzed to measure ventricular mass and ejection fraction (EF), strain and torsion, and mitral early-to-atrial flow rate (E/A), respectively. The tagged images were analyzed by an expert using HARP by Diagnosoft and SinMod by InTag. The tagging analysis was conducted on short-axis slices at the base, midventricular, and apical levels to measure circumferential strain and apical-to-base torsion. Correlation analysis was conducted to evaluate the relationship between HARP and SinMod measurements. Student's t-test was conducted to evaluate the significance of the measurements' differences between HARP and SinMod as well as between patients and $\mathrm{HC}(\mathrm{P}<0.001$ was considered significant).

\section{Results}

As shown in Figure 2, all SinMod measurements were significantly larger than those by HARP. Nevertheless, there existed consistency in the measurements by each technique, as seen by the good correlation between the HARP and SinMod measurements in both normals and

University of Michigan, Ann Arbor, MI 


\begin{tabular}{lcccccc}
\hline \multirow{2}{*}{ Parameter } & \multicolumn{7}{c}{ HC } & \multicolumn{3}{l}{ T1DM } \\
\cline { 2 - 7 } & HARP & SinMod & $\mathbf{R}$ & HARP (P) & SinMod (P) & R \\
\hline Strain, base (\%) & $-20.5 \pm 1.5$ & $-25.1 \pm 2.4$ & 0.73 & $-19.7 \pm 2.1(.35)$ & $-23.8 \pm 2.7(.29)$ & 0.79 \\
Strain, mid (\%) & $-21.9 \pm 1.7$ & $-27.0 \pm 3.2$ & 0.91 & $-21.1 \pm 2.6(.42)$ & $-26.1 \pm 2.8(.51)$ & 0.23 \\
Strain, apex (\%) & $-21.9 \pm 1.5$ & $-30.1 \pm 2.4$ & 0.07 & $-20.7 \pm 2.1(.16)$ & $-29.5 \pm 2.4(.60)$ & 0.29 \\
Strain, global (\%) & $-21.4 \pm 1.2$ & $-27.2 \pm 2.5$ & 0.87 & $-20.5 \pm 2.0(.23)$ & $-26.1 \pm 2.4(.31)$ & 0.48 \\
Torsion (\%) & $3.6 \pm 0.9$ & $6.2 \pm 1.6$ & 0.52 & $4.2 \pm 1.0(.19)$ & $6.5 \pm 1.4(.59)$ & 0.83 \\
\hline * Strain = circumferential strain, Torsion = (basal rotation - apical rotation) / base-to-apex distance, \\
HARP = harmonic phase, HC = healthy control, T1DM = Type-1 Diabetes.
\end{tabular}

Figure 2 Myocardial strain and torsion by HARP and SinMod in HC and T1DM patients.

in the measurements by each technique, as described in the Results section. Most of the discrepancy between the two techniques occurred in apical measurements, which can be attributed to the small anatomical size (i.e. fewer taglines) and lower image quality in the apical images. The insignificant differences between patients and $\mathrm{HC}$ is not unexpected in T1DM due to the young age of the patients and nature of disease progression, e.g. compared to Type-2 diabetes. In conclusion, care should be taken no to mix measurements from different tagging analysis techniques. Further studies including ground-truth measurements are needed to compare the performance of different tagging analysis techniques.

Published: 27 January 2016

doi:10.1186/1532-429X-18-S1-P60

Cite this article as: Ibrahim et al:: HARP Versus SinMod for measuring

regional heart function from tagged CMR images. Journal of

Cardiovascular Magnetic Resonance 2016 18(Suppl 1):P60.
Submit your next manuscript to BioMed Central and take full advantage of:

- Convenient online submission

- Thorough peer review

- No space constraints or color figure charges

- Immediate publication on acceptance

- Inclusion in PubMed, CAS, Scopus and Google Scholar

- Research which is freely available for redistribution

Submit your manuscript at www.biomedcentral.com/submit 